\title{
Academic mobility and financial stability: A case of Erasmus student exchange program
}

\author{
Gulbakyt Kabanbayeva \\ Al-Farabi Kazakh National University, \\ Almaty, Kazakhstan \\ gulq210@gmail.com
}

\section{Maria Gureva}

Department of Economics and Organization of Production

Industrial University of Tyumen

Tyumen, Russian Federation

dorosheva_06@mail.rus

\section{Peter Bielik}

Slovak University of Agriculture in Nitra

Nitra, Slovakia

peter.bielik@uniag.sk

\section{Grzegorz Ostasz}

Rzeszow University of Technology,

Rzeszow, Poland

gost@prz.edu.pl

Abstract. Globalization and digitalization have dramatically changed higher education more than any other sphere of social or economic life. Constant flow of information and free access to all possible data, news, and topics, valuable and fake alike, imposed many challenges for the stakeholders in higher education worldwide. Lecturers and students worldwide became closer thanks to the new technologies, yet they also are drifting apart enclosed in single information bubbles. It is surprising that this digital epoch is seeing an increase in academic mobility worldwide. It appears that young people are willing to leave the comfort of their homes and social networks in order to experience the academic life and culture of other countries. It appears that this trend might also have considerable economic impacts on both sending and receiving countries. Our paper investigates the link between academic mobility and financial stability. We focus on the case study of academic exchange Erasmus program funded by the European Union (EU) and its impact on the financial stability of the Eurozone based on the criteria of the Optimum Currency Area (OCA). Our findings suggest
(C) Foundation of International Studies, 2019 (c) CSR, 2019 
that academic mobility indirectly improves financial stability in four fields: First of all, it enhances future labour mobility. Second, it decreases path-dependence and homogenizes policy preferences. Third, it induces more intensive trade relations. And finally, it increases international solidarity which is very important for such multi-national complex projects as the EU.

Keywords: academic mobility, Erasmus program, financial stability, higher education, Optimum Currency Area, intercultural exchange.

JEL Classification: I22, E42, N14

\section{INTRODUCTION}

The importance of education in the efforts towards national and international development, at the national and at the international levels, has been emphasized on different national, in different countries across the globe, and international platforms (see e.g. Magrane et al., 2018; or Oprea \& Stoica, 2018). Indeed, looking at the Millennium Development Goals (MDGs), goal number two was to achieve universal primary education. Further, the inclusion of education in the Sustainable Development Goals (SDGs), which is SDG goals number four, i. e. "quality education". The United Nations (UN) (2011), demonstrates the importance attached on education as an important economic driver. Indeed, according to Mathew and Balachandran (2018) education levels are considered to be an important indicator of human and economic development at various levels across the globe. Accordingly, with globalization, and the resultant integration, there has been an increased emphasis on the importance of aligning education systems to the emerging globalization phenomenon (Harrison 2018). Furthermore, Linda et al. (2018) stress the importance of the new technologies in higher education that become inevitable due to the wide spread and Internet and social networks that penetrate every sphere of our lives. These endeavors have been orientated towards equipping the global citizens with the skills and competencies required to thrive in an increasingly integrated world and drive human and economic development.

With increased integration at the global level, academic student mobility has emerged as a key initiative (Gulicheva \& Osipova, 2017; or Golob \& Makarovič, 2018). Academic mobility involves moving a person from one educational institution to another, to teach or study, for a period of one year, with an objective of sharing learnings and improving the global academic system (see Altbach \& Knight, 2007). However, there are challenges that impede the effectiveness and efficiency of academic systems from serving the purpose they are intended to at the global level. Moreover, these challenges also impede the effectiveness of academic mobility as an initiative in fostering higher international educational standards. Accordingly, for education systems across the world to play the intended roles in fostering human and economic development, it is important for the policy makers, and all the stakeholders in the education sector wot work together to identify and address various challenges in higher education and academic mobility.

\section{LITERATURE REVIEW}

There are various global challenges facing higher education. A scrutiny of these challenges will show that they are closely related and will have a collective impeding effect on the use of academic programs and the general education systems to achieve the goals of a country and the global community, more so considered in the context of the globalized international community. At the very core of their purpose, higher education institutions have a responsibility of engaging in academic work, including teaching, 
research, and other activities that equip students with the skills and competencies to be productive citizens and foster the development of research and knowledge that promotes human and economic development (Kalyugina et al., 2015; Tvaronavičienè et al. 2017; or Kahle et al. 2018). However, with globalization, institutions of higher learning may have strayed from this mandate, which is one of the main global challenges for higher education and academic mobility (Strielkowski et al. 2018). With regard to the above, Knight (2013) aptly demonstrates the negative effects of internationalization of education, including commercialization of education, diploma and accreditation mills, international rankings and the brain race. In agreement, Shin and Harman (2009) observed that universities have been transformed into for-profit institutions, which has impacted the way courses are delivered, and may also have compromised the quality of higher education.

Essentially, in the article, Knight argues, a position that Shin and Harman concur with, that with internationalization of education, institutions of higher learning may be focusing so much on making more money from the increasing number of enrolees and may stray from providing quality education in response to the demands of the labour market. Such an approach would therefore be deemed as using such institutions to provide students with the papers or credentials that the job market demands of them, rather than imparting the skills, competencies, and the knowledge required to thrive in the job market. It is in this context that Knight (2013) argues that institutions of higher learning may be very much focused on achieving higher rankings in the competitive global education sector and may within the course of doing so not deliver on their mandate in promoting human and economic development. The implications of this situation are that while globalization and the subsequent internationalization of education may have been beneficial in some ways, it may have given rise to other challenges.

There are other aspects directly associated with the nature of the higher education system, which are also challenges to global education and student mobility. One such challenge is curriculum development and implementation. Despite the fact that there has been increased integration brought about by globalization, there still exists differences in the curriculums of different countries across the globe. Indeed, according to Shin and Harman (2009) different countries will develop and implement their own curriculums in line with their national agenda. Accordingly, curriculum disparities across the globe, considered in the context of global education pose a major challenge to global education and academic mobility because when different countries have different curriculums, then it is detrimental to the pursuit of integration. In addition, with such differences, students or instructors may have difficulties moving from one institution to another in line with the academic mobility objectives because they are not familiar with the curriculum used in the other country. It would therefore be important for different countries; governments, governments' agencies, and regulating bodies to work together to foster integration in education to support the globalization agenda. Elken (2017) pointed out that in Europe, there has been a pursuit of standardization through the Bologna Process, which seeks to standardize curriculum, testing, credit hours, and degree award requirements. Altbach and Knight (2007) make similar observation and argue for the internationalization and standardization of curriculum to support integration and academic mobility across the globe. Such an approach would then foster integration and promote global education and academic mobility because a change or cross border movement would not result in a change of curriculum and subsequently, pedagogical methodologies.

Another challenge for global education and academic mobility are the numerous challenges in the environment, more particularly the disruption of jobs, changing work demands, and global development focus. In the recent past, there has been a lot of focus on science and technology, as a driver of economic development, which according to Hendry et al. (2017) has seen a commensurate focus on mathematics, sciences, and other related subjects in curriculum and instructions in institutions of higher learning or in entire academic curriculums. While such a focus may be aligned to the general trends, it may also result in a 
shift of focus from other subjects, such as arts, which in the long term may be detrimental to the global economy.

Indeed, according to De Luna Gallardo et al. (2016), Ushakov et al. (2017) or Mathew and Balachandran (2018) the changes in the skills, competencies, and knowledge required in the labour market, or in line with the national agenda of specific countries, precipitates the development and implementation of curriculums that support the achievement of the desired goals and objectives. Changing demands of the global employer and skills and competencies disparities. These arguments demonstrate that the disruption of jobs and the subsequent skills and competencies requirements, place a commensurate demand on education systems to be more responsive to the demands of the job or labour market which is crucial for the processes such as deepening and fostering EU integration (see Chamberlin, 2015). Similarly, Knight (2013) observed that the changes in the operating in the operating environment, or more specifically, the labour market, may place a lot of pressure on institutions of higher learning necessitated by the need to be more responsive to the demands of the labour market. While universities strive to be innovative and meet the demands of the labour or job market, the rapid changes are placing a lot of demands on universities, especially in regard to curriculum development and implementation vis-à-vis the demands of the labour market. Such a trend necessitates a focus on continuous environmental scanning and collaboration, which will ensure that educational institutions are more responsive to the changes in the operating environment. Indeed, collaboration has been cited as a must use approach in ensuring the responsiveness of the global higher education educational system.

Another challenge for global education and academic mobility is the increasing cost of education. According to Knight (2013), the escalating cost of the traditional university 4-year degree program is becoming prohibitive to the efforts geared at mass higher education or increasing the number of people with such credentials. Indeed, in most countries, as observed by Altbach and Knight (2007), there has been an increase in the cost of acquiring tertiary education, including college diplomas, degrees, and other postgraduate credentials, which may be prohibitive. Indeed, the recommendations by Basillote et al. (2016) that the government of Singapore should create value and strive to decrease the overall cost of education for students is further evidence that the cost of education has been escalating. With an increase in the cost of higher education, students, in the absence of getting a scholarship or other grants, may not be willing and able to move from one institution to another, because such transfers, even in the short-term as is the case in academic mobility, may translate into further increases in the total cost of education for the student. It is therefore imperative, as Stafford-Smith et al. (2017) suggest, for governments and other stakeholders to work together; to collaborate and provide value through reduced cost and improved quality of education to promote global integration and academic mobility to drive human and economic development.

Other challenges for global education and academic mobility include legal and political factors. According to Collins et al. (2017), government and regulatory agencies are also a major challenge to global education and academic mobility. Governments will require students to obtain documents, such as student visas and work permits and may also take other actions which constitute travel regulation and restrictions. Such actions may impede cross border and international movements, which may dissuade students from travelling to other countries for education. In addition, with increased competition globally with the establishment of internationally renowned institutions in local economies such as Singapore, local institutions and students may be disadvantaged, which according to Lim and Pham (2016) may breed hatred or heightened anti-foreign sentiments. Such a trend my combine with the exit of global institutions of higher learnings from global economic hubs such as Singapore, and will be a major challenge to education systems, especially in countries such as Singapore.

International student mobility is one of the key tools how to face all the challenges presented above. Student mobility represents an effective tool how to tackle many issues related to education and labour 
market. This paper uses an example of the EU Erasmus program in order to demonstrate how international student mobility might (among other things) yield in a number of beneficial gains for the financial stability. Even though this process is often happening indirectly and it not easy to trace, multiple body of evidence demonstrates that there are impacts on labour market, banking system, as well as on the other economic and social aspects of everyday life. In the rest of the paper, we will outline our case and provide evidence and arguments for its support.

\section{METHODOLOGY AND DATA}

One of the best and longest-lasting initiatives in student mobility and international cooperation of the universities can be found in European Union (EU). It can boast one of the most popular and long-lasting academic exchange programs called "Erasmus" which celebrated its 30th anniversary last year. Erasmus (and acronym for the "European Community Action Scheme for the Mobility of University Students") program was conceived by the European Commission in June 1987 as a framework fostering the international cooperation in tertiary education (Pépin, 2007; or Hronec and Štrangfeldová, 2013). Even though several EU countries with their own academic exchange programs were against such centralized approach and the original proposition was delayed, the very first years proved to be a great success for the program.

In 1995, Erasmus program was incorporated with other educational initiatives under the name of Socrates, followed by Socrates II in 2000, the Lifelong Learning Program (LLP) in 2007 and transformed into Erasmus+ from January 2014 (see Figure 1). Erasmus+ unites the LLP, Youth in Action and several other programs and is once again becoming a symbol of the integration, representing the EU's commitment to education and training which has been outlined in the Lisbon Treaty (Grove 2013).

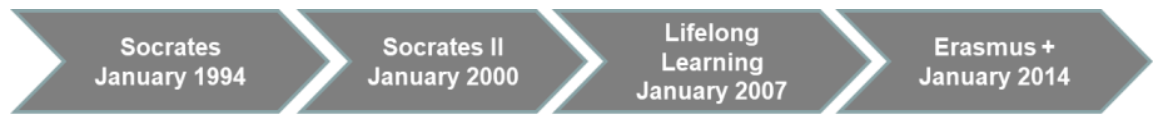

Figure 1. Stages of development of Erasmus program

Source: Own results

In spite of the very short time span between the launch of Erasmus program and the beginning of the new academic year back in 1987, a total of 3244 students enjoyed the benefits of the program during the school year of 1987-1988. Within four years, the number of participants grew more than ten-fold and at the end of the millennia the number of students rose as high as 107 654. Up until now, there were more than 3 million students who took part in Erasmus program (see Figure 2).

Despite its modest start, Erasmus program gained lots of publicity and popularity and is often regarded as one of the flagships of European integration as it represents the benefits of free movements, education spill-overs, as well as cultural exchange (Paptsiba, 2009). The LLP's budget for the period 2007-2013 reached 7 billion EUR which is approximately $0.70 \%$ of the total EU budget and was further approved at a growth rate of $40 \%$ for the next budgetary period (González et al., 2011; or Vassiliou, 2013), despite the cuts in overall EU budget (European Commission, 2013).

The launch of the Erasmus student exchange program was not at all smooth. Yearly budget deficits caused by the recession and the sovereign debt crisis in 2011 and 2012 resulted in $€ 8.5$ billion revenue shortfall and according to the European Commission (2012), it was expected that the first areas to be damaged (leading to the cuts in budgets and funding) would be academic cooperation projects involving schools, adults and vocational training. This threat has outraged most participants and led to launching of 
the very first European Citizens' Initiative Fraternite 2020 which managed to defend Erasmus and similar educational projects (González et al., 2011).

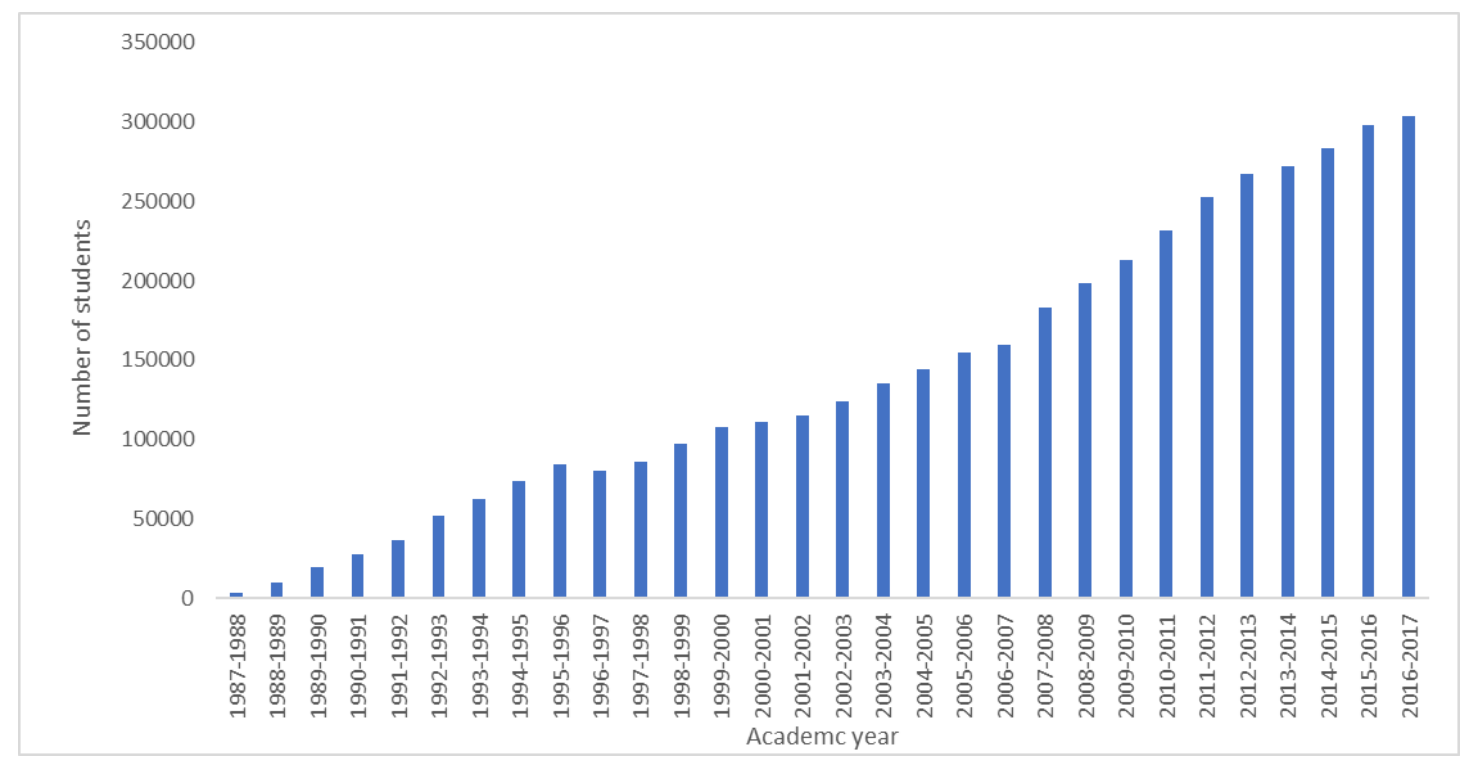

Figure 2. Number of students participating in Erasmus program (1987-2017)

Source: European Commission (2018)

The average monthly EU grants received by the students participating in Erasmus program are quite modest and range from 270 EUR in France, Germany or UK to 150 EUR in Bulgaria, Estonia, or Poland (European Funding Guide 2018). In order to solve this issue, many countries complement the EU grant from local, regional or national sources. Even so, the popularity of Erasmus among students is soaring (see Figure 3). Perhaps, this is due to the fact that young Europeans understand the potential of Erasmus and all the advantages it provides in a form of increasing the employability through acquiring new skills and knowledge, learning new languages, getting to know new cultures and habits and building social ties all around European continent. A recent study by the European Union showed that participation in Erasmus program increases the probability of finding employment by over $40 \%$ (European Union, 2017).

And this is not to mention the favourable demographic impact of the student mobility. In a study entitled "The Erasmus impact study" it has been estimated that about $25 \%$ of the students participating in the program met their long-term partner while studying abroad and for its whole duration, Erasmus was probably responsible for over 1 million newborn babies (European Union, 2017).

Thence, Erasmus program represents a non-negligible share of the EU educational budget. One should realize, that Erasmus + and other student exchange and training programs would be the first to undergo budget cuts in case of economic complications (e.g. severe economic crisis). This, however, jeopardizes the security that such program should be offering and may discourage participation - especially of those from less developed regions for whom such help would be most beneficial. That is, on the one hand, EU promotes Erasmus as the symbol of integration success, yet on the other hand, it is prepared to use it as a crisis buffer, although this very project might be one of the factors preventing and mitigating such crises.

Among a plethora of theories that attempt to predict the severity of crises, one of them that focuses on the feasibility and costs of currency areas - the theory of the Optimum Currency Area (OCA) developed by Robert Mundell (1961) - is particularly interesting with regard to our thesis of Erasmus program being able to serve as a tool for endorsing financial stability in the EU. The hypothesis we are trying to scrutinize 
is that Erasmus exchange programme has a positive impact on financial stability and a negative impact on the costs incurred once a country (or a block of countries such as the EU) is hit by an economic recession.

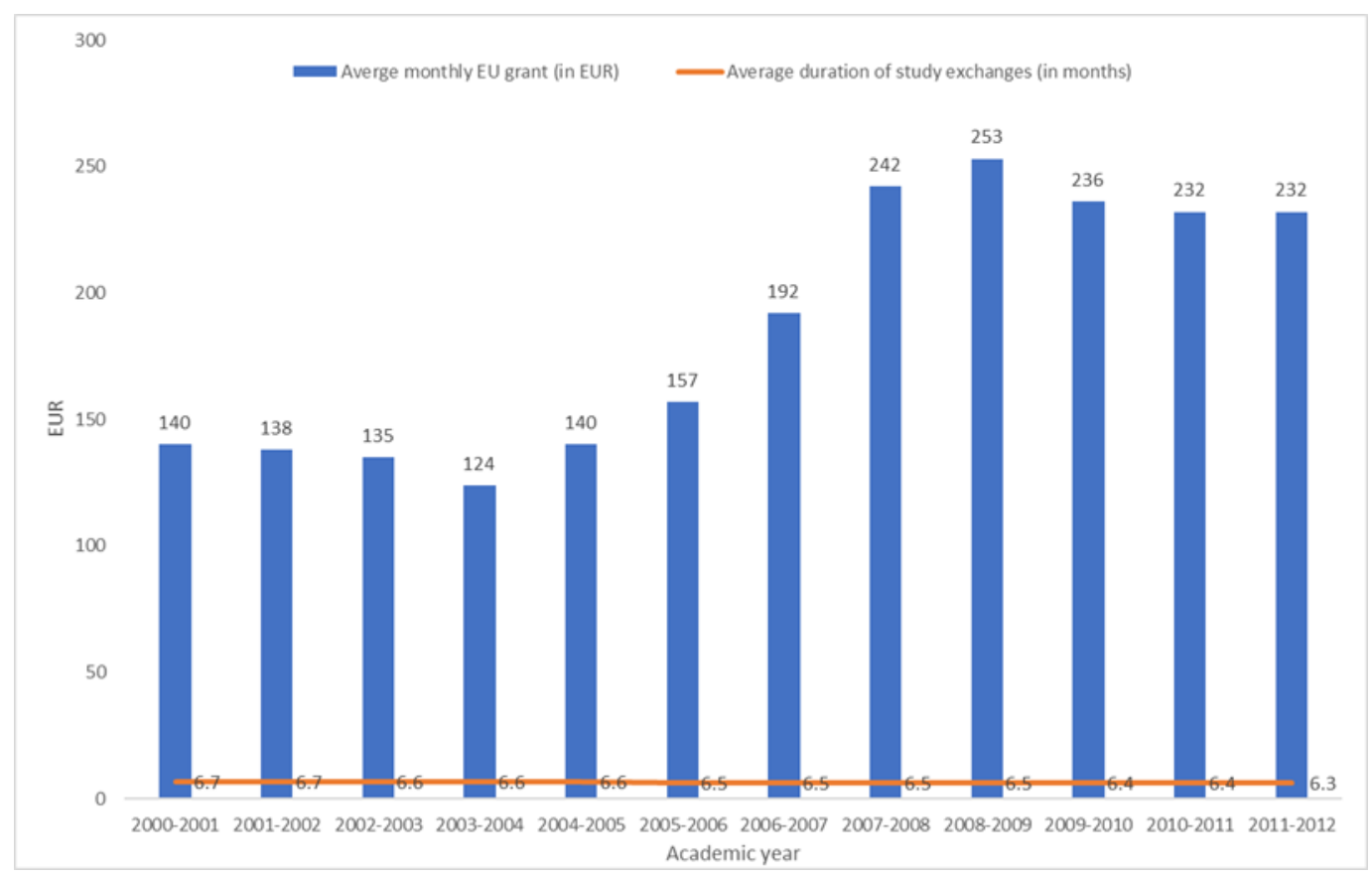

Figure 3. Average monthly EU grant (in EUR) and duration of stay (in months) in 2000-2012 Source: European Commission (2018)

It becomes clear that there are active ways currency areas can improve their future stability. Although they may not be always perfectly apparent and often can take years or decades to manifest, one can see that it is crucial for the currency areas to pursue these long-term strategies (possibly along with other short-term ones) to ensure stable development and prevent unnecessary turmoil.

\section{RESULTS AND IMPLICATIONS}

It has long been debated whether or not the EU is or is not an Optimum Currency Area. In economic theory, Optimum Currency Area (also called an "optimal currency region" represents a geographical region in which the economic efficiency from sharing a single currency would maximize the benefits the entire region (Quah 2016). The seven criteria of OCA (four original one coined by Mundell (1961) and three additional ones added later by his colleagues and followers) are presented in Table 1 that follows.

The early theories on OCA by Mundell (1961), McKinnin (1963), or Kennen (1994), based their predictions on Keynesian macroeconomic theory and were rather pessimistic. They predicted very high costs caused by rising unemployment due to the shocks. However, this view was moderated by the monetary economists in the 1970s who claimed that workers focused on real (rather than nominal) wages and the adverse effects were not so strong (Matthes, 2009). 
Optimum Currency Area (OCA) criteria

\begin{tabular}{|c|c|c|}
\hline No. & Criterion & Comments \\
\hline 1 & Labour mobility across the region & $\begin{array}{l}\text { Physical ability to travel (visas, workers' rights, etc.), } \\
\text { lack of cultural barriers to free movement (such as } \\
\text { different languages) and institutional arrangements }\end{array}$ \\
\hline 2 & $\begin{array}{l}\text { Openness with capital mobility and price and wage } \\
\text { flexibility across the region }\end{array}$ & $\begin{array}{l}\text { Forces of supply and demand automatically } \\
\text { distribute goods and money to where they are } \\
\text { required }\end{array}$ \\
\hline 3 & $\begin{array}{l}\text { Existence of the risk-sharing system (automatic } \\
\text { fiscal transfer mechanism) }\end{array}$ & $\begin{array}{l}\text { Redistributing money to areas and sectors which are } \\
\text { adversely affected by the first two characteristics }\end{array}$ \\
\hline 4 & Similar business cycles for member countries & $\begin{array}{l}\text { Recession is one country is likely to be followed by } \\
\text { the others }\end{array}$ \\
\hline 5 & Production diversification & \multirow{3}{*}{$\begin{array}{l}\text { Assumptions of monopolistic competition and the } \\
\text { theory of the firm and consumer }\end{array}$} \\
\hline 6 & Homogeneous preferences & \\
\hline 7 & Commonality of destiny & \\
\hline
\end{tabular}

Source: Own compilations based on Mundel (1961) and Kennen (1994).

One of the disadvantages of the OCA is that it only provides the intuitive guidelines for studying whether the countries in question form a currency union. The theory does not specify any thresholds that the member countries need to surpass in order to achieve the OCA provisions. In spite of these limitations, some authors tried to develop indices and several countries used the OCA criteria (either implicitly or explicitly) in order to decide whether a given country should join the Eurozone (see e.g. Rose and Engel, 2002; or Baldwin and Wyplosz, 2012). However, none of these measures were widely accepted and the concept of OCA is unable to give us concrete answers.

The theory that changed the way economists looked at the OCA theory and its main criteria was the endogeneity theory developed by Frankel and Rose (1996). They used a sample of 20 OECD countries and developed an empirical link between the intensity of trade between countries and their business cycle synchronization. Consequently, they argued that by joining a currency union the costs of international trade decrease and the volume increases, therefore the business cycle synchronization would follow (Frankel and Rose 1996).

These views were fostered by the actual launch of the Eurozone project in 1999 and 2002 that introduced a single European currency and provided a new impulse to the economists who studied various forms of currency unions. These researchers then analyzed the OCA theory in the view of Eurozone and refined their theories using newly available sources of data. For example, Fidrmuc (2004) used a dataset from the 1990s and encompassing the data on intra-industry trade in Europe. Although he failed to detect any link between the general trade volume and the business cycles, he found significant evidence of the facts that intra-industry trade induces business cycle convergence. Also, Schiavo (2008) confirmed that endogeneity (especially on the European financial markets) and showed that capital markets integration increases the output correlation between countries.

On the other hand, Matthes (2009) claims that the endogeneity force can be offset by divergence inducing effects, especially the real interest rate decreases in the outset of the European monetary union. Other researchers contrast the OCA endogeneity theory with the specialization theory which claims that integration pushes countries towards a more specialized production (Mongelli, 2005). Such shift would make the currency union members less diversified and more vulnerable to supply shocks.

Finally, some researchers adopt a more conservative approach and point out that one carefully distinguishes the effects of different EU-wide developments (either initiatives or policy implications) and the effect of Eurozone and Euro currency (Willett et al. 2010). They claim that only further research can 
show the real endogeneity effects, aligning with some of the original claims of Frankel and Rose (1998) who admitted that the effects could take decades to truly manifest

With regard to the above, one can find a link between OCA theory provisions and academic exchange programs, just like Erasmus. In general, Kincl et al. (2013) divide te research on academic exchange program can be divided into two wide categories: i) answering the question, whether these programs serve any purpose or, ii) whether these programs represent a waste of public money. The second approach examines specific features and the impacts (which they find to be mostly positive).

Messer and Wolter (2006) compare the costs and benefits of exchange programs. They study a sample of students from Switzerland and find that while participation in exchange programs is correlated with better starting salaries and higher probability of postgraduate studies, this relationship is not causal. On the other hand, Keogh and Russel-Roberts (2009), conclude from a similar type of study that student mobility does lead to knowledge and skills spillovers. Moreover, they argue that the international experience provides participants with improved ability to compare and critically assess development in their home country.

One of the most pronounced effects of student mobility is an increase in their overall labour mobility. Parey and Waldinger (2010) show that the student mobility experience increases the probability of working in a foreign country by $15 \%$. This effect is mostly concentrated in the countries in which the students previously studied. This result implies that part of the skills acquired is labour market specific.

In addition, Erasmus exchange program was also envisaged to promote the European identity. While some conclude that these effects are offset by the student pre-selection and claim that Erasmus participants are actually those who already shared the common European identity (Kuhn 2012), the majority of research confirms that this aim is being successfully pursued and students identify themselves as more European once returned (Demirkol, 2013). Table 2 that follows offers a comprehensive classification of some of the selected relevant studies on this topic.

Table 2

Erasmus program and OCA - a classification of selected studies

\begin{tabular}{|l|l|}
\hline \multicolumn{1}{|c|}{ Study } & \multicolumn{1}{c|}{ Overview of main results } \\
\hline Parey and Waldinger (2010) & $\begin{array}{l}\text { Student mobility increases the probability of working in a foreign } \\
\text { country by 15\%. }\end{array}$ \\
\hline Wolfeil (2010) & $\begin{array}{l}\text { Mobility enhancing effect - around 30\% students later return to seek } \\
\text { employment (case of Polish mobility to Germany). }\end{array}$ \\
\hline Myers (2011) & $\begin{array}{l}\text { Studying in foreign country increases probability of making friends } \\
\text { from that country and set up businesses with them. }\end{array}$ \\
\hline Kuhn (2012) & $\begin{array}{l}\text { Significant increase in cross-border mobility in the EU for high-skilled } \\
\text { and university educated professionals }\end{array}$ \\
\hline Demirkol (2013) & $\begin{array}{l}\text { Erasmus student mobility programs have a positive effect on the } \\
\text { cultural integration and human rights in Turkey }\end{array}$ \\
\hline Jocobone and Moro (2015) & $\begin{array}{l}\text { Erasmus has a positive impact on the perception of university students } \\
\text { and increases cultural enhancement, personal development and } \\
\text { foreign language proficiency. }\end{array}$ \\
\hline Mitchell (2015) & $\begin{array}{l}\text { Participation in Erasmus significantly impacts on identification with } \\
\text { being European and identification with the EU principles }\end{array}$ \\
\hline European Union (2017) & $\begin{array}{l}\text { Participation in Erasmus program increases the probability of finding } \\
\text { employment by over 40\%. }\end{array}$ \\
\hline
\end{tabular}

Source: Own results based on the review of the literature

One would probably agree that the relationship of students' mobility and the subsequent labour market mobility is a very straightforward one. While studying abroad, students get to know foreign country, its habits and culture, as well as its "cultural psyche". All this accumulated knowledge and skills can contribute to their decision on whether to move and work abroad. Although it is not entirely general (the increased 
willingness to migrate partially works only for the former host country) it is apparent that additional aggregation should eliminate this issue. For example, Wolfeil (2010) recorded the mobility enhancing effect using a specific case of Polish student mobility to Germany showing that around 30\% students return to the country to seek employment.

Studying abroad (albeit for a short period of time) might change the consumption patterns as a result of availability of other goods and services than those available in the home country. Some of the changes disappear once the students return (the famous principle of the "cultural shock"), however others remain and make the consumer to search for foreign goods or services she or he liked when staying abroad. These preferential swings might be positively correlated with the length of the stay abroad and therefore might be significantly larger for a half-year programs that Erasmus offers. This relatively small population of apt consumers could create a demand platform for import of the goods and possibly spread the interest in these previously unknown goods throughout the rest of the population. Moreover, the period of stay abroad can also be regarded as the international trade-enhancing event due to the fact that the money spent in a foreign country (and partly paid by the EU funds) can be seen as imports. However, one should omit this effect as relatively insignificant.

David (1985) developed a theory of path-dependence and claimed that: "it is sometimes not possible to uncover the logic (or illogic) of the world around us except by understanding how it got that way". Indeed, at times we see that the world around us is significantly influenced by coincidence. When nobody takes the time to deal with this coincidence everything stays that way (or is path-dependent).

The same goes to the formation of political and legislative preferences which might be formed and shaped up by the previous experience. Some countries may incline to unpopular policies that prevent inflation because of the bad memory of hyperinflation, while the others may focus on fighting unemployment. These preferences can be caused by the events that occurred in the past (path-dependency) rather than rational thinking in the present. Sharing one's experience and cultural background might become a great source of inspiration and influence one's beliefs. This is similar to the results of Keogh and RusselRoberts (2009) who studied the improved ability of critical assessment. Once people are aware of reasons that underlie different policies, they discover the freedom to choose the better one or at least understanding the one they dislike. Both these effects promote homogeneity in policy preferences.

The research in social psychology demonstrated that "proximity, interaction and mere exposure are strong determinants of affection" (Myers 2011). To say it differently, staying in a foreign country increases the probability of making friends from that country and establishing dense social ties. Zsembik and Beeghley (1996) show that there is a positive correlation between the ethnic solidarity and the amount of inter-ethnic ties. It might be that these results can be applied to the case of whole nations and countries. Both findings actually imply that there is a positive influence of studying in a foreign country (which includes interactions with foreigners) on personal solidarity. This effect is also propelled by the heterogeneity of nations whose students can intercept during such programmes. They get to know the culture of the host country, and they might get a chance to discover the cultures and habits of other exchange students.

Nevertheless, it is also important to note that the majority of the described and analysed effects would not take place immediately. For the effects on labour mobility to take place, it might take several years before the students join the labour market and the benefits come through. For solidarity issue, the time lag could be even longer as far as most of the students generally need to achieve a more advanced levels of their career path in order to gain stronger influence. The same applies for preferences homogeneity - as the income increases, the influence of the student exchange programs also increases, and the policy preferences become more relevant. When it comes to the openness effect, one can see that it also has a significant time lag, as far as consumption habits of individuals depend on the level of income. 


\section{CONCLUSIONS AND DISCUSSIONS}

All in all, there are numerous challenges for global education and academic mobility, which if not addressed, may impede the intended purpose of education, to foster human and economic development. In the globalized world, differences in curriculum, increasing cost of higher education, changes in the environment, government regulation, and compromised quality and purpose of education, are major challenges to global education and academic mobility. To address these challenges, it is important for the academic institutions, governments, and governmental agencies, to work together with other stakeholders to mitigate the challenges and ensure that education, at the global level, fosters human and economic development.

Our results show that the student exchange programs (represented in our case by EU Erasmus program) might have a considerable effect on several of the seven OCA criteria. Moreover, we determine that they are affected by a foreign study experience in a positive way. In addition, we show student exchange programs such as Erasmus have a beneficial impact on the long-term stability of EMU and that they might actually decrease the costs of economic shocks or recessions.

It appears that the benefits of an academic experience abroad could be expressed in a form of seven key criteria: (i) on the personal level the participants of the student exchange programs can improve their employability, (ii) academic exchange programs serve as a platform for learning new and improving current foreign language skills, (iii) the participants of academic exchange programs improve their self-sufficiency, (iv) and train intercultural skills; further, (v) academic exchange programs enable universities to exchange best practise, (vi) academic exchange programs allow to compare results and identify their strengths and weaknesses, (vii) academic exchange programs make the learning process more transparent. Apart from the mentioned benefits it could also be possibly used as a long-run policy tool to improve the stability of Eurozone and decrease costs of asymmetric shocks. We might conclude that student mobility improves the overall standing in the OCA criteria and increases economic and financial stability.

\section{REFERENCES}

Altbach, P., \& Knight, J. (2007). The internationalization of higher education: Motivations and realities. Journal of Studies in International Education, 11(3-4), 290-305. doi: 10.1177/1028315307303542

Baldwin, R., \& Wyplosz, C. (2012). The economics of European integration, 4th edition. Berkshire: McGraw-Hill, London.

Basillote, L., Gradus, Y., Lamb, J., Sharoni, T., \& Thing, M. (2016). Singapore's Higher Education Cluster. Harvard Business School. Retrieved from: https://www.isc.hbs.edu/resources/courses/moc-course-atharvard/Documents/pdf/student-projects/Singapore\%20Higher\%20Education\%202016.pdf

Chamberlin, G. (2015). Coordinating Monetary and Fiscal Policies in the Open Economy. International Economics Letters, 4(1), 15-25. doi: 10.24984/iel.2015.4.1.2

Collins, F. L., Ho, K. C., Ishikawa, M., \& Ma, A. H. S. (2017). International student mobility and after-study lives: the portability and prospects of overseas education in Asia. Population, Space and Place, 23(4), e2029. doi: $10.1002 /$ psp.2029

Daniela, L., Visvizi, A., Gutiérrez-Braojos, C., \& Lytras, M. (2018). Sustainable Higher Education and TechnologyEnhanced Learning (TEL). Sustainability, 10(11), 3883. doi: 10.3390/su10113883

De Luna Gallardo, G., Korneeva, E., \& Strielkowski, W. (2016). Integration of migrants in the EU: lessons and implications for the EU migration policies. Journal of International Studies, 9(2), 244-253. doi:10.14254/2071$8330.2016 / 9-2 / 19$ 
Demirkol, A. Y. (2013). The role of educational mobility programs in cultural integration: A study on the attitudes of Erasmus students in Turkey toward the accession of Turkey to European Union. The Anthropologist, 16(3), 653661. doi: 10.1080/09720073.2013.11891390

Elken, M. (2017). Standardization of (higher) education in Europe-policy coordination 2.0?. Policy and Society, 36(1), 127-142. doi: 10.1080/14494035.2017.1278873

European Commission (2013). Figures and documents. Retrieved from: http://ec.europa.eu/budget/mff/figures/index_en.cfm

European Funding Guide (2018). How much money can you get on the Erasmus+ programme? Retrieved from: http://www.european-funding-guide.eu/articles/financing-tips/how-much-money-can-you-get-erasmusprogramme (accessed on 2 December 2018)

European Union (2017). The Erasmus Impact study. Retrieved from: https://publications.europa.eu/en/publicationdetail/-/publication/13031399-9fd4-11e5-8781-01aa75ed71a1

Fidrmuc J. (2004). The endogeneity of the optimum currency area criteria, intra-industry trade, and EMU enlargement. Contemporary Economic Policy, 22(1), 1-12. doi: 10.1093/cep/byh001

Frankel J., \& Rose, A. (1998). The Endogeneity of the Optimum Currency Area Criteria. The Economic Journal, 108(449), 1009-1025. doi: 10.1111/1468-0297.00327

Golob, T., \& Makarovič, M. (2018). Student Mobility and Transnational Social Ties as Factors of Reflexivity. Social Sciences, 7(3), 46. doi: 10.3390/socsci7030046

González, C. R., Bustillo Mesanza, R., \& Mariel, P. (2011). The determinants of international student mobility flows: an empirical study on the Erasmus programme. Higher Education, 62(4), 413-430. doi: 10.1007/s10734-0109396-5

Grove, J. (2013). Horizon 2020 and Erasmus budgets approved. Times Higher Education. Retrieved from: http://www.timeshighereducation.co.uk/news/horizon-2020-and-erasmus-budgetsapproved/2009234.article

Gulicheva, E., \& Osipova, M. (2017). Program-target method of pricing for international educational services. Czech Journal of Social Sciences, Business and Economics, 6(1), 21-27. doi: 10.24984/cjssbe.2017.6.1.3

Harrison Neil. 2018. Using the Lens of 'Possible Selves' to Explore Access to Higher Education: A New Conceptual Model for Practice, Policy, and Research. Social Sciences, 7(10), 209. doi: 10.3390/socsci7100209

Hendry, A., Hays, G., Challinor, K., \& Lynch, D. (2017). Undertaking Educational Research Following the Introduction, Implementation, Evolution, and Hybridization of Constructivist Instructional Models in an Australian PBL High School. Interdisciplinary Journal of Problem-Based Learning, 11(2), 7. doi: 10.7771/15415015.1688

Hronec, S., \& Štrangfeldová, J. (2013). Socio-Economic Effects of Education in the Context of Economic Return. The New Educational Review, 32(2), 172-183.

Jacobone, V., \& Moro, G. (2015). Evaluating the impact of the Erasmus programme: skills and European identity. Assessment \& Evaluation in Higher Education, 40(2), 309-328. https://doi.org/10.1080/02602938.2014.909005

Kahle, J., Risch, K., Wanke, A., \& Lang, D. (2018). Strategic Networking for Sustainability: Lessons Learned from Two Case Studies in Higher Education. Sustainability, 10(12), 4646. doi: 10.3390/su10124646

Kalyugina, S., Strielkowski, W., Ushvitsky, L., \& Astachova, E. (2015). Sustainable and secure development: facet of personal financial issues. Journal of Security \& Sustainability Issues, 5(2), 297-304. doi: 10.9770/jssi.2015.5.2(14) 
Kennen, P. (1994). The Theory of Optimum Currency Areas: An Eclectic View. In Exchange Rates and the Monetary System. Aldershot, England: Edward Elgar Publishing Limited, 41-60.

Keogh, J., \& Russel-Roberts, E. (2009). Exchange programmes and student mobility: Meeting student's expectations or an expensive holiday?. Nurse Education Today, 29(1), 108-116. doi: 10.1016/j.nedt.2008.07.006

Kincl, T., Novák, M., \& Štrach, P. (2013). A cross-cultural study of online marketing in international higher educationa keyword analysis. New Educational Review, 32(2), 49-65.

Knight, J. (2013). The changing landscape of higher education internationalization - for better or worse?. Perspectives: Policy and practice in Higher Education, 17(3), 84-90. doi: 10.1080/13603108.2012.753957

Kuhn, T. (2012). Why educational exchange programmes miss their mark: Cross-border mobility, education and European identity. JCMS: Journal of Common Market Studies, 50(6), 994-1010. doi: 10.1111/j.14685965.2012.02286.x

Lim, S., \& Pham, B. (2016). Digital Connections and Disjunctures of Migrant Students. Identities and Subjectivities, 4, 315331. doi: 10.1007/978-981-287-023-0_6

Magrane, D., Morahan, P., Ambrose, S., \& Dannels, S. (2018). Competencies and Practices in Academic Engineering Leadership Development: Lessons from a National Survey. Social Sciences, 7(10), 171. doi: 10.3390/socsci7100171

Mathew, R., \& Balachandran, U. (2018). Comparison of the Educational System in Singapore and India and How India Can Reform Its Current Practices to Improve the Quality of Learning. International Journal of Advanced Research and Development, 3(1), 245-248

Matthes, J. (2009). Ten years EMU — Reality test for the OCA endogeneity hypothesis, economic divergences and future challenges. Intereconomics, 44(2), 114-128. doi: 10.1007/s10272-009-0285-Z

Messer, D., \& Wolter, S. C. (2007). Are student exchange programs worth it?. Higher Education, 54(5), 647-663. doi: 10.1007/s10734-006-9016-6

Mitchell, K. (2015). Rethinking the 'Erasmus Effect' on European Identity. JCMS: Journal of Common Market Studies, 53(2), 330-348. doi: 10.1111/jcms.12152

Mongelli, F. P. (2005). What is European Economic and Monetary Union Telling Us About the Properties of Optimum Currency Areas?. Journal of Common Market Studies, 43(3), 607-635. doi: 10.1111/j.0021-9886.2005.00571.x

Mundell, R. (1961). A Theory of Optimum Currency Areas. The American Economic Review, 51(4), 657-665.

Myers, D. (2011). Exploring Social Psychology. Gth edition, McGraw-Hill, New York.

Oprea, O-R., \& Stoica, O. (2018). Capital Markets Integration and Economic Growth. Montenegrin Journal of Economics, 14(3), 23-35. doi: 10.14254/1800-5845/2018.14-3.2

Papatsiba, V. (2009). European higher education policy and the formation of entrepreneurial students as future European citizens. European Educational Research Journal, 8(2), 189-203. doi: 10.2304/eerj.2009.8.2.189

Parey, M., \& Waldinger, F. (2010). Studying abroad and the effect on international labour market mobility: Evidence from the introduction of ERASMUS. The Economic Journal, 121(551), 194-222. doi: 10.1111/j.14680297.2010.02369.x

Pépin, L. (2007). The History of EU Cooperation in the Field of Education and Training: how lifelong learning became a strategic objective. European Journal of Education, 42(1), 121-132. doi: 10.1111/j.1465-3435.2007.00288.x

Quah, C-H. (2016). Germany versus the United States: Monetary dominance in the Eurozone. Economies, 4(2), 8. doi: $10.3390 /$ economies 4020008 
Schiavo, S. (2008). Financial integration, GDP correlation and the endogeneity of optimum currency areas. Economica, 75(297), 168-189.

Shin, J. C., \& Harman, G. (2009). New challenges for higher education: Global and Asia-Pacific perspectives. Asia Pacific Education Review, 10(1), 1-13. doi: 10.1007/s12564-009-9011-6

Stafford-Smith, M., Griggs, D., Gaffney, O., Ullah, F., Reyers, B., Kanie, N, Stigson, B., Shrivastava, P., Leach, M., \& O'Connell, D. (2017). Integration: the key to implementing the Sustainable Development Goals. Sustainability Science, 12(6), 911-919. doi: 10.1007/s11625-016-0383-3

Strielkowski, W., Kiseleva, L. S., \& Popova, E. N. (2018). Factors determining the quality of university education: students' views. Integration of Education, 22(2), 220-236. doi: 10.15507/1991-9468.091.022.201802.220-236

Tvaronavičienè, M., Shishkin, A., Lukáč, P., Illiashenko, N., \& Zapototskyi, S. (2017). Sustainable economic growth and development of educational systems. Journal of International Studies, 10(3), 285-292. doi: 10.14254/2071$8330.2017 / 10-3 / 21$

United Nations. (2011). Education Is Key Driver of Economic Growth, Catalyst for Empowering Women, Deputy Secretary-General Tells Commission on Status of Women at Opening. Retrieved from: https://www.un.org/press/en/2011/dsgsm540.doc.htm

Ushakov, D., Bandurina, N., \& Shkodinsky, S. (2017). Country's welfare as an efficiency factor in fiscal policy promoting economic growth. Montenegrin Journal of Economics, 13(2), 121-127. doi:10.14254/1800-5845/2017.132.7

Vassiliou, A. (2013). Erasmus+ : 40\% budget boost for the world's biggest and best mobility programme. Retrieved from: https://www.eumonitor.eu/9353000

Willett, T. D., Permpoon, O., \& Wihlborg, C. (2010). Endogenous OCA analysis and the early euro experience. The World Economy, 33(7), 851-872. doi: 10.1111/j.1467-9701.2010.01268.x

Zsembik, B., \& Beeghley, L. (1996). Determinants of ethnic group solidarity among Mexican Americans: A research note. Hispanic Journal of Behavioral Sciences, 18(1), 51-62. doi: 10.1177/07399863960181006 